\title{
SEPARATION OF SUBSTANCES RELATED TO ASCORBIC ACID
}

\author{
By Dr. L. W. MAPSON and Dr. S. M. PARTRIDGE \\ Low Temperature Station for Research in Biochemistry and Biophysics, Cambridge
}

$\mathrm{T}$ HE method of paper partition chromatography has in recent years been widely used for the separation, detection and estimation of closely related compounds. We thought it of interest to determine to what oxtent it could be used to differentiate l-ascorbic acid from some of its isomers and from other osely related dienols. Simple titration methods using $2: 6$ dichlorophenolindophenol give a reliable estimate of the vitamin content of most of the common foodstuffs, as shown by the close correspondence between chemical and biological results ${ }^{1-3}$. A method proposed by Roe and Kuether4, which is based on the formation of a coloured condensation product of $2: 3$ diketogulonic acid with $2: 4$ dinitrophenylhydrazone, also gives results which are generally in agreement with those of the indophenol method.

However, neither of these methods will differentiate $l$-ascorbic acid from its isomers or related dienols, such as reductone, reductic acid, hydroxytetronic acid, and dihydroxymaleic acid. Some of these substances are known to be produced during the processing of foods ${ }^{5-7}$, and $d$-isoascorbic acid has been added to quick-frozen fruits to prevent browning.

Methods have been proposed whereby the reaction of the indophenol dye with ascorbic acid may be made more specific. Such methods include one based on the different rates of condensation of $l$-ascorbic acid and other dienols with formaldehyde ${ }^{8-10}$, and one based on the different rates of reaction with indophenol dye ${ }^{11}$; but these modifications will not allow differentiation of $l$-ascorbic acid from either hydroxy. tetronic or $d$-isoascorbic acids.

A tentative method recently proposed by Trotter, Thompson and Wokes ${ }^{12}$, based on difference in the infra-red spectra of these substances, may permit of a certain differentiation, although as pointed out by the authors the spectra are so complex that in a mixture of substances differentiation would be very difficult.

The following work was therefore carried out to determine how far paper partition chromatography would permit a qualitative detection of $l$-ascorbic acid in the presence of these other dienols. To what extent this has been accomplished is indicated below, and since the results are generally promising it is hoped to continue this work to enable a more quantitative estimate to be made.

The behaviour of ascorbic acid and dehydro. ascorbic acid on filter paper chromatograms has been reported by one of us ${ }^{13}$. In this work the reaction of ascorbic acid with cold silver nitrate - ammonia was used to locate its position on the chromatogram. Dehydroascorbic acid was located by its reaction with the same reagent on heating the paper, but when this substance was prepared by oxidation of ascorbic acid with iodine, interference due to iodide ions was observed (note added in proof to ref. 13, March 1948).

While silver nitrate - ammonia is a useful spraying reagent where it is also desired to establish the presence of reducing sugars or the oxidation products of the dienols, it is frequently of advantage to use a more specific reagent, and the indophenol dye commonly used for the estimation of ascorbic acid serves well for this purpose. The reagent was prepared by dissolving $2: 6$ dichlorophenolindophenol $(0.8 \mathrm{gm}$.$) in water (1 litre) and diluting the solution$ with an equal volume of ethanol. On spraying the chromatograms with the dye solution, ascorbic acid and related dienols react immediately and appear as sharply bounded colourless spots on the dark blue background.

The apparatus and technique adopted was generally that described by Consden, Gordon and Martin ${ }^{14}$ for the amino-acids. A large number of different solvent mixtures was investigated to determine those most suitable for the separation of members of this series. In general, the presence of acid in the solvent mixture appeared to be necessary $(a)$ to suppress the ionization of the acidic substances and thus to prevent 'tailing', (b) to assist in stabilizing the dienols during the course of the run. Nevertheless, successful results were obtained by use of the weakly basic solvent collidine, and a fraction distilled from technical collidine (b.p. $172^{\circ}$ ) gave well-defined spots and reproducible mobilities. In order to suppress the catalytic effect of copper, irrigation of the chromatograms was carried out in the presence of a low concentration of hydrogen cyanide obtained by the addition of a small quantity (5-10 mgm.) of potassium cyanide crystals to the aqueous solution contained in the bottom of the tank. With hydrogen cyanide present, the use of stainless steel troughs was permissible, although in experiments of this sort glass troughs may be advantageous.

The accompanying table shows the results obtained with the three solvent mixtures found to be most suitable. These were made up as follows : (1) butanol, glacial acetic acid and water were shaken together in the proportion $40: 10: 50$ by volume $e^{13}$ and the upper layer used in the trough; (2) glacial acetic acid was added to freshly steam-distilled phenol, to a con-

\begin{tabular}{|c|c|c|c|c|c|c|}
\hline & \multicolumn{3}{|c|}{ Colour reaction } & \multicolumn{3}{|c|}{$\begin{array}{c}R_{F} \text { values on Whatman No. } 1 \text { paper at room } \\
\text { temp. }\left(15-18^{\circ} \mathrm{C} .\right)\end{array}$} \\
\hline & Indophenol & $\begin{array}{l}\mathrm{AgNO}_{3}-\mathrm{NH}_{3} \\
\text { Room temp. }\end{array}$ & $\begin{array}{c}\mathrm{AgNO}_{3}-\mathrm{NH}_{3} \\
100^{\circ} \mathrm{C} .\end{array}$ & $\begin{array}{c}(1) \\
\text { Butanol-acetic } \\
(\mathrm{KCN})\end{array}$ & $\begin{array}{c}(2) \\
\text { Phenol-acetic } \\
\text { (KCN) }\end{array}$ & $\begin{array}{c}\text { (3) } \\
\text { Collidine } \\
\text { (KCN) }\end{array}$ \\
\hline $\begin{array}{l}\text { Ascorbic acid } \\
\text { Isoascorbic acid } \\
\text { Hydroxytetronic acid } \\
\text { Reductone } \\
\text { Reductic acid } \\
\text { Dehydroascorbic acid }\end{array}$ & $\begin{array}{l}\text { White } \\
\text { White } \\
\text { White } \\
\text { White } \\
\text { White }\end{array}$ & $\begin{array}{l}\text { Black } \\
\text { Black } \\
\text { Black } \\
\text { Black } \\
\text { Black } \\
\text { Light brown }\end{array}$ & $\begin{array}{c}\text { Black } \\
\text { Black } \\
\text { Black } \\
\text { Black } \\
\text { Black } \\
\text { Dark brown }\end{array}$ & $\begin{array}{l}0 \cdot 37 \\
0 \cdot 38 \\
0 \cdot 63 \\
0 \cdot 63 \\
0 \cdot 64 \\
0 \cdot 41\end{array}$ & $\begin{array}{l}0 \cdot 35 \\
0 \cdot 40 \\
0 \cdot 62 \\
0 \cdot 66 \\
0 \cdot 78 \\
0 \cdot 38\end{array}$ & $\begin{array}{l}0 \cdot 40 \\
0 \cdot 41 \\
0 \cdot 49 \\
0 \cdot 46 \\
0 \cdot 40 \\
0 \cdot 44\end{array}$ \\
\hline
\end{tabular}


centration of 1 per cent by volume, and the mixture shaken with an equal volume of water; after equilibration at room temperature the lower layer was used in the trough; (3) technical collidine was refluxed for $6 \mathrm{hr}$. over solid potassium permanganate and then distilled; a middle fraction (b.p. $172^{\circ}$ C.) was shaken with water and the upper layer used in the trough.

Since the presence of hydrogen cyanide precluded the use of a constant-temperature room, the $R_{F}$ values $^{14}$ given in the table (average values from five determinations) were obtained at room temperature. It is clear from the results in the table that the greatest separations were obtained by the use of the phenolacetic acid mixture, and it is of particular interest that the separation of ascorbic acid and $d$-isoascorbic acid from mixtures of the two is possible in this solvent. It should be pointed out, however, that the problem of separating these two substances when present in extracts of biological material may be more difficult and has not yet been attempted.

The spots due to the dienols were regular in shape, but that due to dehydroascorbic acid was markedly elliptical and was frequently accompanied by a second smaller spot of low and rather variable $R_{F}$ value. $\left(R_{F}\right.$ in butanol-acetic acid, $0.04-0.07$.) Since these secondary spots approximately coincided with those given by the sodium salt of diketogulonic acid, it was inferred that their presence was due to the opening of the lactone ring of dehydroascorbic acid during the course of the run.

We wish to acknowledge the assistance of $\mathrm{Mr}$. D. F. Elsden and to thank Prof. T. Reichstein for a supply of reductone and reductic acid.

${ }^{1}$ Harris, I. J., and Ray, S. W., Lancet, 228, 71 (1935).

${ }^{2}$ Birch, T. W., Harris, L. J., and Ray, S. W., Biochem. J., 27, 90 (1933).

${ }^{3}$ Harris and Olliver, Biochem. J., 36, 155 (1942).

4 Roe and Kuether, J. Biol. Chem., 47, 399 (1943).

'Harris, L. J., Nature, 132, 27 (1933)

- Mapson, L. W., Nature, 152, 13 (1943)

${ }^{7}$ Wokes, F., Organ, J. G., Ducan, J., and Jacoby, F. C., Nature, 152, 14 (1943).

- Lugg, J. W. H., Aust, J, Exp, Biol, 20, 273 (1942).

- Mapson, L. W., J. Soc. Chem. Indust., 62, 223 (1943).

${ }^{10}$ Snow, G. A., and Zilva, S. S., Biochem. J., 37, 630 (1943).

1 Harris, L. J., and Mapson, L. W., Brit. J. Nut., 1, 7 (1947).

${ }^{12}$ Trotter, I. F., Thompson, H. W., and Wokes, F., Biochem. J., 42 , 601 (1948).

${ }^{13}$ Partridge, S. M., Biochem. J., 42, 238 (1948). 14 Consden, R., Gordon, A. H., and Martin, A. J. P., Biochem. J.,
38, 224 (1944).

2nto

\section{THIRD WORLD FORESTRY CONGRESS}

$\mathrm{T}$ HE first World Forestry Congress was held in Rome in $1926^{\circ} \mathrm{ml}$ the second in Budapest in 1936. The thir fras convened in Helsinki at the invitation o the overnment of $\mathrm{F}$ inland in accordance with a ropess adopted at the third session of the FA. (Food) and Agriculture Organisation) Confele. Twenty-nine nations were represented, the Congress being held during July 10-20 this year. Representatives of international organisations were present, such as the United Nations and its Economic Commission for Europe, the F.A.O. of the United Nations, the International Union of Forest Research Organisations and the Scandinavian Forestry Union. 406 full and 125 associate delegates attended.
The first meeting was held on July 11 in the Great Hall of the University. The Congress was opened by the Prime Minister of Finland, Mr. K. A. Fagerholm, and welcomed by His Excellency J. K. Paasikivi, president of the Republic of Finland. Messages were brought from the Secretary-General of the United Nations and the Director-General of F.A.O. and read by their representatives, Mr. D. Roy Cameron and M. Marcel Leloup.

A provisional programme had been laid down by the organising committee and was accepted, the work being allocated to five sections: (1) Sylvics and Sylviculture; (2) Forest Surveys; (3) Forest Economics including Forest Policy; (4) Forest Utilization; (5) Forest Industries. As it turned out the divisions of some of the sections were not sufficiently clear cut, and overlapping took place, especially in the case of sections 1 and 3. Prof. Eino Saari, who had been president of the organising committee, was elected president of the Congress with two copresidents (U.S.A. and U.S.S.R.) and five vicepresidents. Chairmen and vice-chairmen of the sections were appointed with rapporteurs and so forth. Mr. M. H. Leppo (Finland) was elected secretary-general.

The opening ceremony concluded, the Congress then elected the officers as above-mentioned. The second plenary session commenced in the afternoon and was devoted to papers of world-wide interest by representatives of F.A.O. with one additional paper. The F.A.O. papers were read by M. Marcel Leloup on "General Aspects of World Forestry" and Mr. Harrison on "Forest Resources and Human Needs of Wood". The additional paper was by Prof. E. P. Stebbing on "Catchment Areas and Water Supplies", and the last "Le passage de la Forêt Vierge à la Forêt Amenagée" by M. François. The other two papers by F.A.O. representatives were read the following morning. They dealt mainly with sylviculture, but in the second there was controversial matter ; the writer claimed that high-quality timber was no longer required but only small-sized timber quickly grown. A Canadian delegate put the opposite case, pointing out that Canada had for long provided parts of the world with high-quality timber and considered its production essential to fill certain market requirements-a view strongly supported by many delegates.

Since a large number of papers read had been submitted to the organising committee, with brief abstracts, before the Congress opened, it is difficult to say what influence on the progress of the Congress in its various sections was exerted by the opening F.A.O. papers. But inevitably points made in these latter came up in the discussions which took place in every section, in each of which an F.A.O. representative was on the platform. Unfortunately and perhaps inevitably, some of these discussions and the subsequent resolutions they gave rise to in a particular section were reproduced in meaning, if not in actual words, in one or more of the others.

For the general outcome there can be little doubt that the discussions and the resolutions they gave rise to and accepted, after drafting, by the Congress as a whole, should have a greater chance of producing results than was the case after the Rome 1926 Congress, at which I was present and from which few practical results were achieved. As to the second at Budapest, war broke out too soon after to make it possible to say that governments had realized their neglected responsibilities in these matters. 